\title{
An HIV-positive status and short term perioperative mortality - a systematic review
}

\author{
Yoshan Moodley ${ }^{\mathrm{a} *}$ and Kumeren Govender ${ }^{\mathrm{b}}$ \\ ${ }^{a}$ Discipline of Anaesthesiology and Critical Care Medicine, University of KwaZulu-Natal, Durban, South Africa \\ ${ }^{b}$ Nelson R. Mandela School of Medicine, University of KwaZulu-Natal, Durban, South Africa \\ *Corresponding author, email: moodleyyo@ukzn.ac.za
}

\begin{abstract}
Background: A contemporary summary describing the impact of an HIV-positive status on short term perioperative mortality is lacking.

Objective: To collate and summarise published data related to short term perioperative mortality from studies comparing HIVpositive and HIV-negative patient groups.

Method: We conducted a systematic review of the published literature by performing structured searches of two medical literature databases. Pre-defined inclusion/exclusion criteria were used to identify potentially relevant manuscripts. Further screening of the reference lists of eligible manuscripts, as well as a prior systematic review was also performed to identify any additional manuscripts that may have been relevant. Data retrieved from eligible manuscripts included, amongst other variables: study and population descriptions, surgical category (cardiac or noncardiac surgery), as well the incidence of short term perioperative mortality. Crude odds ratios were calculated for each eligible manuscript to describe the association between HIV status and short term perioperative mortality.

Results: Our systematic review consisted of 12 manuscripts describing 12 studies. The majority of manuscripts described studies conducted in countries with a low burden of HIV infection. Most manuscripts described findings from a noncardiac surgery setting. Crude associations between an HIV-positive status and a higher odds of short term perioperative mortality were noted for data from 2 of the 12 manuscripts, while the association was unclear in the remaining 10 manuscripts.

Conclusion: Evidence supporting a higher odds of short term perioperative mortality in patients with an HIV-positive status is unconvincing. Further research is required to adequately investigate this.
\end{abstract}

Keywords: HIV, mortality, perioperative, surgery

\section{Introduction}

There are over 30 million people living with HIV infection worldwide. ${ }^{1}$ The advent of antiretroviral therapy has increased life expectancy in persons with HIV infection, and it is therefore likely that a proportion of these patients will require surgery for HIVrelated or HIV-unrelated pathologies during their lifetime. ${ }^{2}$ It is estimated that over 230 million patients (irrespective of HIV status) undergo surgical procedures each year, with almost $0.5 \%$ of these patients suffering perioperative mortality. ${ }^{3} \mathrm{~A}$ systematic review by Madiba et al., which was published in 2009 , suggested that the impact of an HIV-positive status on the incidence of perioperative mortality appears unclear. ${ }^{2}$ We decided to perform an updated systematic review of the published literature in order to collate and summarise data related to short-term perioperative mortality from studies with HIV-positive and HIV-negative patient groups.

\section{Method}

We conducted a parallel search of PubMed and Web of Science databases. In PubMed, we searched using a combination of phrases/keywords and using a set of relevant MeSH terms (Table 1). We chose to search PubMed with both of these options to improve the sensitivity of the search. There is no controlled vocabulary (MeSH) search function within the Web of Science, thus searches on this database were performed using only phrases. Searches were performed on both databases until 20 August 2015.

In addition, the reference list of the systematic review conducted by Madiba et al., ${ }^{2}$ was also screened for potentially relevant manuscripts. Abstracts of studies identified from the literature search were screened using the inclusion and exclusion criteria specified in Table 2. The reference lists of included manuscripts were hand-searched for relevant studies which might not have been identified during the literature search. The quality of included studies was evaluated using the Newcastle-Ottawa scale. We did not extend our search to "grey area" literature. Our decision to exclude data from "grey area" literature might have introduced publication bias; however, the "grey area" literature is often not peer-reviewed and, in the case of conference abstracts, may not have provided enough information to be included in the review. Two authors independently screened the articles for inclusion in the review, and the opinion of an expert was sought in the event of a dispute.

The following data elements were extracted from all included manuscripts: author; country where the study was conducted; year of publication; surgical category (cardiac or noncardiac surgery); surgical specialty; and, sample size of the studies. The characteristics of included studies are presented descriptively. Potential associations between an HIV-positive status and a higher risk of short term perioperative mortality are presented as crude odds ratios (with 95\% confidence intervals), which were calculated using additional study data extracted from each included manuscript. Calculation of the crude odds ratios and 95\% confidence intervals was performed using the Statistical Package for the Social Sciences (SPSS) version 23.0 (IBM Corp., USA). 
Table 1: Search strategy implemented during this systematic review

\begin{tabular}{|c|c|c|}
\hline Database & Query & MeSH term/Phrases \\
\hline \multirow[t]{7}{*}{ PubMed } & HIV & $\begin{array}{l}\text { HIV [MeSH], HIV Infections [MeSH], Acquired Immunodeficiency } \\
\text { Syndrome [MeSH], HIV [Title/Abstract], Human Immunode- } \\
\text { ficiency Virus [Title/Abstract], Acquired Immunodeficiency } \\
\text { Syndrome [Title/Abstract], AIDS [Title/Abstract], HIV/AIDS [Title/ } \\
\text { Abstract] }\end{array}$ \\
\hline & Perioperative setting & $\begin{array}{l}\text { Perioperative Period [MeSH], Perioperative Care [MeSH], } \\
\text { Intraoperative Period [MeSH], Postoperative Period [MeSH], Pre- } \\
\text { operative Period [MeSH], Intraoperative Complications [MeSH], } \\
\text { Postoperative Complications [MeSH], Monitoring, Intraoperative } \\
\text { [MeSH], Perioperative* [Title/Abstract], Pre-operative* [Title/ } \\
\text { Abstract], Intra-operative* [Title/Abstract], Post-operative* } \\
\text { [Title/Abstract], Perioperative* [Title/Abstract], Post-surgery } \\
\text { [Title/Abstract] }\end{array}$ \\
\hline & Mortality & $\begin{array}{l}\text { Mortality [MeSH], Death [MeSH], Death* [Title/Abstract], Mortal- } \\
\text { ity* [Title/Abstract] }\end{array}$ \\
\hline & Risk factors & $\begin{array}{l}\text { Risk [MeSH], Risk Factors [MeSH], Odds Ratio [MeSH], Risk [Title/ } \\
\text { Abstract], Risk Factor* [Title/Abstract], Odds Ratio* [Title/Ab- } \\
\text { stract], Risk Ratio* [Title/Abstract], Hazard Ratio* [Title/Abstract] }\end{array}$ \\
\hline & Observational studies & $\begin{array}{l}\text { Cross-Sectional Studies [MeSH], Case-Control Studies [MeSH], } \\
\text { Cohort Studies [MeSH], Cross-sectional study* [Title/Abstract], } \\
\text { Cross sectional study* [Title/Abstract], Case-control study* [Ti- } \\
\text { tle/Abstract], Case control study* [Title/Abstract], Cohort study* } \\
\text { [Title/Abstract], Cohort [Title/Abstract] }\end{array}$ \\
\hline & Adult population & $\begin{array}{l}\text { Adult [MeSH], Aged [MeSH], Middle Aged [MeSH], Young Adult } \\
{[\mathrm{MeSH}]}\end{array}$ \\
\hline & Human research & Humans [MeSH] \\
\hline Web of Science & All & $\begin{array}{l}\text { Searched using phrases as outlined in PubMed search (No MeSH } \\
\text { search function in Web of Science database) }\end{array}$ \\
\hline
\end{tabular}

Table 2: Inclusion/exclusion criteria used in this systematic review

\begin{tabular}{|l|}
\hline Inclusion Criteria \\
\hline Manuscripts related to HIV infection \\
\hline Original research manuscripts \\
\hline Research conducted in humans \\
\hline Research conducted in adults \\
\hline English language \\
\hline Surgical procedures performed \\
\hline Mortality outcome reported \\
\hline
\end{tabular}

Mortality outcome measured at patient discharge from hospital, or within 30 days following surgery

Presence of an HIV-negative comparator group

\section{Exclusion Criteria}

Not related to HIV infection (ie. "AIDS" defined as an assistive tool/device)

Not original research manuscripts (ie. Narrative reviews, case reports, etc.)

No human research

Research conducted in children

Not English language

No surgical procedures performed

No mortality outcome reported

Mortality outcome not measured at patient discharge, or measured $>30$ days following surgery

No HIV-negative comparator group present

\section{Results}

The results of our literature search of PubMed and the Web of Science are illustrated in Figure 1. Our electronic search yielded a total of 87 manuscripts. Screening the reference list of the review compiled by Madiba et al., ${ }^{2}$ yielded 2 additional relevant manuscripts. A total of 5 of the total 89 manuscripts were duplicates. Following review of the abstracts of the remaining 82 unique manuscripts, 19 manuscripts were selected to undergo full text review. Reasons for exclusion of 65 manuscripts included:

- Not original research manuscript (3 manuscripts);

- Not in English (4 manuscripts);

- Research included children (3 manuscripts);

- No comparator group (15 manuscripts);

- Non-human research (2 manuscripts);
- No mortality outcome reported (6 manuscripts);

- No HIV-positive population (24 manuscripts);

- Reporting long term mortality (7 manuscripts); and,

- Study not conducted in surgical patients (1 manuscript).

Following full text screening of the 19 manuscripts, there were 7 manuscripts which were found to be ineligible for the following reasons:

- No surgery (3 manuscripts);

- No comparator group (1 manuscript);

- HIV population combined with cancer population (2 manuscripts);

- No mortality outcome reported (1 manuscript). 


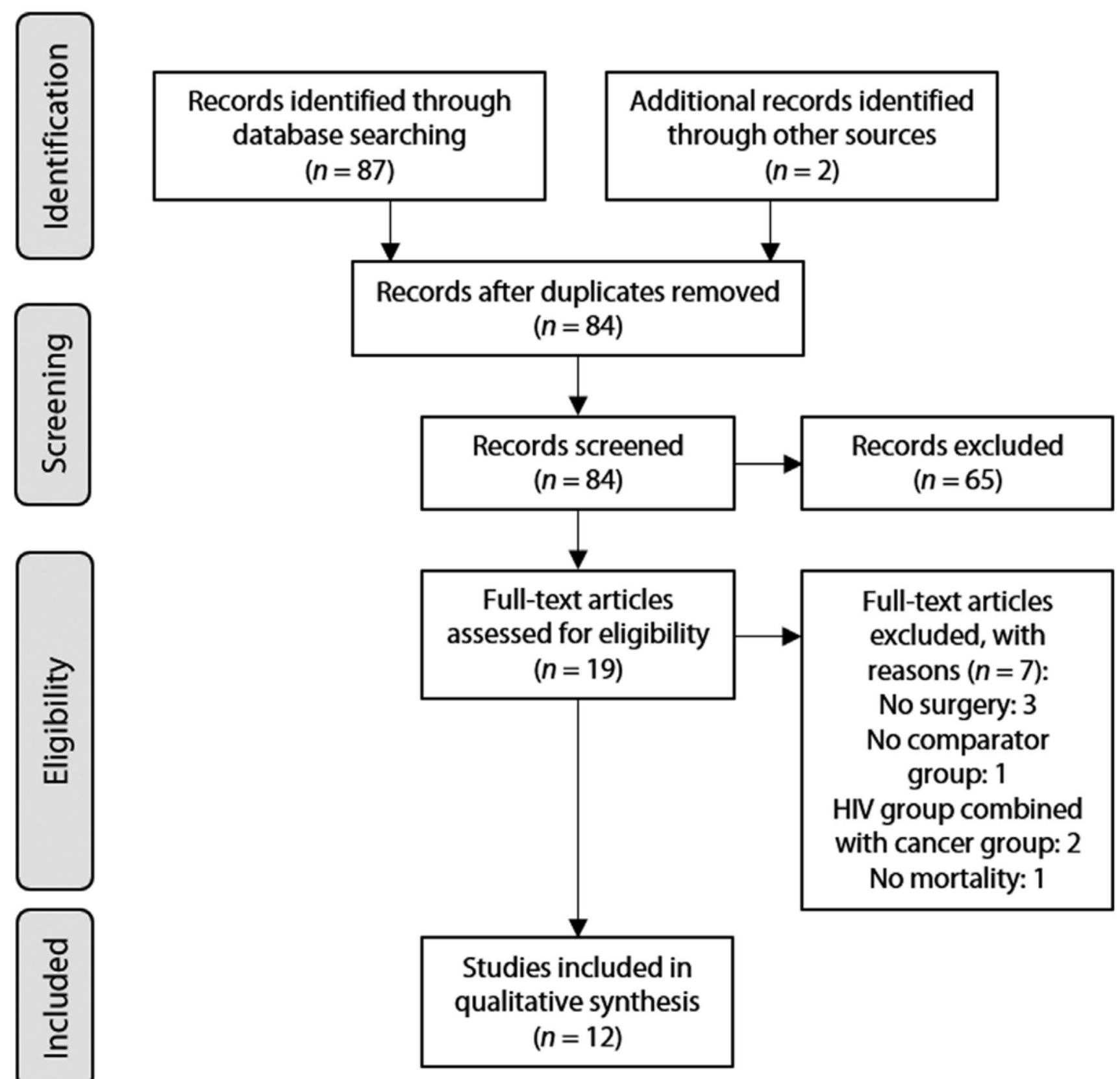

Figure 1: Flow diagram showing study selection.

In addition, we screened the reference lists of the remaining 12 manuscripts in order to identify other potentially eligible studies for inclusion in our systematic review, however no additional manuscripts were found. Therefore, this systematic review comprised 12 eligible manuscripts. ${ }^{4-15}$

A description of all eligible manuscripts evaluated in this systematic review is shown in Table 3 . There were 12 eligible manuscripts reporting on 12 unique studies conducted in 5 countries (8 studies in USA, 2 studies in South Africa, 1 study in Malawi, and 1 study in France/Italy). ${ }^{4-15}$ Three studies $5^{5,10,12}$

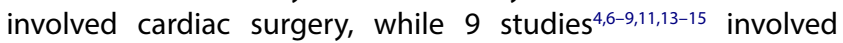
noncardiac surgery. Surgical specialties represented in this systematic review were diverse. Most studies had total sample sizes $<100$ patients, with a few exceptions. The studies included in this systematic review were of acceptable quality. Crude odds ratios calculated for each study found associations between an
HIV-positive status and short term perioperative mortality in 2 studies (both noncardiac surgery studies), ${ }^{9,15}$ while the association was unclear in the remaining 10 studies. ${ }^{4-8,10-14}$

\section{Discussion}

The findings of our systematic literature search highlight the scarcity of published literature related to the impact of HIV status on short term perioperative mortality, despite the growing burden of HIV infection in the surgical setting and the incidence of mortality following surgical procedures worldwide. Our findings also indicate that the majority of research was conducted in countries with a low burden of HIV infection (USA and France/ Italy contributed 9 of the 12 studies). ${ }^{1}$ Data from the majority of included manuscripts in our systematic review (3 of the 3 manuscripts reporting cardiac surgery, and 7 of the 9 studies reporting noncardiac surgery) did not demonstrate any clear association between an HIV-positive status and a higher crude 
Table 3: Characteristics of studies included in this systematic review

\begin{tabular}{|c|c|c|c|c|c|c|c|}
\hline $\begin{array}{c}\text { Author (Year of } \\
\text { Publication) }\end{array}$ & Country & $\begin{array}{l}\text { Newcastle- } \\
\text { Ottawa Score }\end{array}$ & $\begin{array}{l}\text { Surgical } \\
\text { Category } \\
\text { (Cardiac/ } \\
\text { Noncardiac) }\end{array}$ & $\begin{array}{l}\text { Surgical } \\
\text { Procedure }\end{array}$ & $\begin{array}{c}\text { Sample Size } \\
\text { (HIV-positive + } \\
\text { HIV-negative, } \\
\text { related to } \\
\text { mortality } \\
\text { outcome } \\
\text { results) }\end{array}$ & $\begin{array}{c}\text { Sample Size } \\
\text { (HIV-positive } \\
\text { only) }\end{array}$ & $\begin{array}{l}\text { Crude Odds } \\
\text { Ratio (95\% } \\
\text { Confidence } \\
\text { Intervals) for } \\
\text { short term } \\
\text { perioperative } \\
\text { mortality }\end{array}$ \\
\hline $\begin{array}{l}\text { Boccara et al. } \\
(2008)^{5}\end{array}$ & Italy, France & 7 & Cardiac & $\begin{array}{l}\text { Coronary artery } \\
\text { bypass graft }\end{array}$ & 81 & 27 & $1.98(0.04-102.58)$ \\
\hline $\begin{array}{l}\text { Mutyaba et al. } \\
(2014)^{10}\end{array}$ & South Africa & 5 & Cardiac & Pericardiectomy & 121 & 14 & $0.22(0.01-3.93)$ \\
\hline $\begin{array}{l}\text { Polanco et al. } \\
(2014)^{12}\end{array}$ & USA & 9 & Cardiac & $\begin{array}{l}\text { Coronary artery } \\
\text { bypass graft, } \\
\text { Valve surgery }\end{array}$ & 810940 & 1239 & $0.79(0.55-1.10)$ \\
\hline $\begin{array}{l}\text { Ayers et al. } \\
(1993)^{4}\end{array}$ & USA & 8 & Noncardiac & Mixed & 49 & 24 & $1.05(0.23-4.78)$ \\
\hline $\begin{array}{l}\text { Cacala et al. } \\
(2006)^{6}\end{array}$ & South Africa & 7 & Noncardiac & Mixed & 350 & 135 & $1.00(0.32-3.11)$ \\
\hline $\begin{array}{l}\text { Hooker et al. } \\
(2012)^{7}\end{array}$ & USA & 9 & Noncardiac & $\begin{array}{l}\text { Lobectomy, } \\
\text { Bilobectomy, } \\
\text { Pneumonecto- } \\
\text { my, Other lung } \\
\text { resection }\end{array}$ & 2452 & 22 & $0.92(0.05-15.31)$ \\
\hline $\begin{array}{l}\text { Jones et al. } \\
(2002)^{8}\end{array}$ & USA & 9 & Noncardiac & Mixed & 130 & 43 & $3.19(0.51-19.84)$ \\
\hline $\begin{array}{l}\text { Louis et al. } \\
(2007)^{9}\end{array}$ & USA & 9 & Noncardiac & Caesarian section & 54659 & 378 & $13.15(4.02-43.07)$ \\
\hline Orkin $(2013)^{11}$ & USA & 6 & Noncardiac & $\begin{array}{l}\text { Wide excision of } \\
\text { perineal lesions }\end{array}$ & 20 & 6 & $2.23(0.04-124.21)$ \\
\hline $\begin{array}{l}\text { Redman et al. } \\
(2014)^{13}\end{array}$ & South Africa & 6 & Noncardiac & Vascular & 225 & 73 & $1.20(0.34-4.24)$ \\
\hline $\begin{array}{l}\text { Stawicki et al. } \\
(2005)^{14}\end{array}$ & USA & 8 & Noncardiac & Trauma & 1173 & 559 & $1.16(0.61-2.20)$ \\
\hline $\begin{array}{l}\text { Young et al. } \\
(2013)^{15}\end{array}$ & Malawi & 6 & Noncardiac & $\begin{array}{l}\text { Internal fixation } \\
\text { of femoral } \\
\text { fractures }\end{array}$ & 128 & 23 & $24.53(1.14-529.36)$ \\
\hline
\end{tabular}

odds of short term perioperative mortality. ${ }^{4-8,10-14}$ Our systematic review identified 2 studies wherein data demonstrated associations between an HIV-positive status and a higher crude odds of short term perioperative mortality., ${ }^{9,15}$ However, this finding should be interpreted with caution. It is likely that these two studies were underpowered to investigate short term perioperative mortality in patients with HIV infection. This is supported by the wide confidence intervals obtained for the crude odds ratios obtained from the two aforementioned studies. It is also possible that challenges in the delivery of healthcare services in both studies might have played an underlying role in the majority of mortality observed in the HIVinfected group. For instance, in the study of Young et al., ${ }^{15}$ there was no perioperative prophylaxis for venous thromboembolism due to financial constraints within the study setting. All patients in the HIV-infected group who died postoperatively in the study of Young et al., ${ }^{15}$ were thought to have suffered a pulmonary embolism. Access to HIV care and treatment might have played an underlying role in the mortality observed in the study of Louis et al. ${ }^{9}$ In that study, HIV-infected cesarean section patients were reported less likely to have had access to prenatal care when compared with HIV-uninfected cesarean section patients. Louis et al. also noted that opportunistic infection was the primary cause of death in all HIV-infected patients who died, the majority of whom were diagnosed with AIDS. Antiretroviral therapy use (which could have averted some of the observed deaths) was not described by Louis et al. Considering their findings regarding access to prenatal care, it is tempting to speculate that a proportion of HIV-infected women who were eligible to receive antiretroviral therapy (and thereby reduce their risk of acquiring opportunistic infections) did not have access to HIV care and treatment. The overall finding of our systematic review is in agreement with the findings of the review conducted by Madiba et al., in 2009. ${ }^{2}$ An HIV-positive status alone should not be a reason to argue against surgical intervention as the bulk of the published evidence suggests no higher odds of short term perioperative mortality in patients who are HIV-positive.

There were limitations to this systematic review. Firstly, we were unable to perform an electronic search of EMBASE as our institution does not provide access to this database. However, we feel that a search of combined PubMed and Web of Science (which includes 22 separate databases) databases was adequate for the purposes of the review. Furthermore, the lack of published studies describing perioperative mortality in HIV-positive and HIV-negative patient groups was also evident in the systematic review conducted by Madiba et al. ${ }^{2}$ The small number of published studies also limited our ability to conduct a subsequent meta-analysis. Obvious heterogeneity between studies (for instance cardiac versus noncardiac surgery categories, and differences in surgical specialty groups) also contributed to precluding a meta-analysis. The majority of studies were from countries with a low HIV burden, and more research conducted 
in countries with a higher burden of HIV infection would be required to provide a better estimate of risk.

\section{Conclusion}

In summary, evidence supporting a higher odds of short term perioperative mortality following surgery in patients with an HIV-positive status is unconvincing. A larger collection of studies, in particular those conducted in countries with a high burden of HIV infection, is required to support an appropriate meta-analysis on this topic. Currently, an HIV-positive status alone should not be used as a reason to argue against surgical intervention.

Funding - The first author was supported by a postdoctoral fellowship awarded by the National Research Foundation.

Acknowledgements - The first author was supported by a postdoctoral fellowship awarded by the South African National Research Foundation (NRF). The content of this manuscript is solely the responsibility of the authors and does not necessarily represent the official views of the NRF. The authors declare that there are no potential conflicts of interest related to this research.

\section{Conflicts of Interest - None.}

\section{References}

1. Murray CJ, Ortblad KF, Guinovart C, et al. Global, regional, and national incidence and mortality for HIV, tuberculosis, and malaria during 1990-2013: a systematic analysis for the Global Burden of Disease Study 2013. Lancet. 2014;384:1005-70.

2. Madiba TE, Muckart DJ, Thomson SR. Human immunodeficiency disease: how should it affect surgical decision making? World J Surg. 2009;33:899-909.

3. Weiser TG, Regenbogen SE, Thompson KD, et al. An estimation of the global volume of surgery: a modelling strategy based on available data. Lancet. 2008;372:139-44.
4. Ayers J, Howton MJ, Layon AJ. Postoperative complications in patients with human immunodeficiency virus disease. Chest. 1993;103:18007.

5. Boccara F, Cohen A, Angelantonio E, et al. Coronary artery bypass graft in HIV-infected patients: a multicenter case control study. Curr HIV Res. 2008;6:59-64.

6. Čačala SR, Mafana E, Thomson SR, et al. Prevalence of HIV status and CD4 counts in a surgical cohort: their relationship to clinical outcome. Ann R Coll Surg Engl. 2006;88:46-51.

7. Hooker CM, Meguid RA, Hulbert A, et al. Human immunodeficiency virus infection as a prognostic factor in surgical patients with nonsmall cell lung cancer. Ann Thorac Surg. 2012;93:405-12.

8. Jones $S$, Schechter $C B$, Smith $C$, et al. Is HIV infection a risk factor for complications of surgery? Mt Sinai J Med. 2002;69:329-33.

9. Louis J, Landon MB, Gersnoviez RJ, et al. Perioperative morbidity and mortality among human immunodeficiency virus-infected women undergoing cesarean delivery. Obstet Gynecol. 2007;110:385-90.

10. Mutyaba AK, Balkaran S, Cloete $R$, et al. Constrictive pericarditis requiring pericardiectomy at Groote Schuur Hospital, Cape Town, South Africa: causes and perioperative outcomes in the HIV era (1990-2012). J Thorac Cardiovasc Surg. 2014;148(3058-3065):e3051.

11. Orkin BA. Perineal reconstruction with local flaps: technique and results. Tech Coloproctol. 2013;17:663-70.

12. Polanco A, Itagaki S, Chiang $Y$, et al. Changing prevalence, profile, and outcomes of patients with HIV undergoing cardiac surgery in the United States. Am Heart J. 2014;167:363-8.

13. Redman LA, Naidoo P, Biccard BM. HIV, vascular surgery and cardiovascular outcomes: a South African cohort study. Anaesthesia. 2014;69:208-13.

14. Stawicki SP, Hoff WS, Hoey BA, et al. Human immunodeficiency virus infection in trauma patients: where do we stand? J Trauma. 2005;58:88-93.

15. Young S, Banza LN, Hallan G, et al. Complications after intramedullary nailing of femoral fractures in a low-income country. Acta Orthop. 2013;84:460-7. 